Article

\title{
Opuntia humifusa Supplementation Increased Bone Density by Regulating Parathyroid Hormone and Osteocalcin in Male Growing Rats
}

\author{
Junyong Kang ${ }^{1}$, Jinho Park ${ }^{1}$, Seong Hee Choi ${ }^{2}$, Shoji Igawa ${ }^{3}$ and Youngju Song ${ }^{1, *}$ \\ 1 Laboratory of Sports Nutrition, Sunmoon University, Asan, 336-708, Republic of Korea; \\ E-Mails: garcia60@sunmoon.ac.kr (J.K.); jinho0418@hanmail.net (J.P.) \\ 2 Department of Food Science, Sunmoon University, Asan, 336-708, Republic of Korea; \\ E-Mail: choish@sunmoon.ac.kr \\ 3 Department of Healthcare, Nippon Sport Science University, Yokohama, 227-0033, Japan; \\ E-Mail: igawa@nittai.ac.jp
}

* Author to whom correspondence should be addressed; E-Mail: song6711@sunmoon.ac.kr; Tel.: +82-41-530-2239; Fax: +82-41-530-2810.

Received: 2 May 2012; in revised form: 24 May 2012 / Accepted: 28 May 2012 /

Published: 4 June 2012

\begin{abstract}
We investigated the effect of Opuntia humifusa (O. humifusa) supplementation on bone density and related hormone secretion in growing male rats. Sixteen six-week-old male Sprague-Dawley rats were randomly divided into two groups; control diet group (CG, $n=8$ ), and experimental diet group (EG, $n=8)$. The rats in the CG were given a control diet and those in the EG were given 5\% O. humifusa added to the control diet for eight weeks. The serum OC level of the EG was significantly higher than that of the $\mathrm{CG}$, and the serum parathyroid hormone (PTH) level of EG was significantly lower than that of the CG. In addition, the femoral and tibial BMD of the EG were significantly higher values than those of the $\mathrm{CG}$, and the tibial $\mathrm{BMC}$ of the EG was significantly higher than that of the CG. These results suggest that $O$. humifusa supplementation has a positive effect on bone density by suppressing PTH and increasing the OC level in growing male rats.
\end{abstract}

Keywords: O. humifusa; bone density; parathyroid hormone; osteocalcin; rat 


\section{Introduction}

Osteoporosis is one of the most common metabolic bone diseases, and it increases the risk of fracture by reducing bone strength [1]. Although the period during which peak bone mass is attained differs according to bone type, most bones grow rapidly through puberty, and peak bone mass is attained at approximately 25 years old, after which bone mass is gradually decreased [2]. However, previous studies have suggested that the bone mass is not only relatively decreased but also at a higher risk of fracture in obese children because the bone mineral density (BMD) and bone mineral content (BMC) are lower in obese children than in normal children $[3,4]$. Nevertheless, sufficient mineral intake in the growth period, such as calcium $\left(\mathrm{Ca}^{2+}\right)$ [5] and magnesium $\left(\mathrm{Mg}^{2+}\right)$ [6], can reduce the risk of fracture by increasing $\mathrm{BMD}$ and $\mathrm{BMC}$, and can also reduce the risk of osteoporosis or fracture in elderly individuals [7].

Among the mineral nutrients, $\mathrm{Mg}^{2+}$ is essential for physiological function in various tissues and organs [8]. In particular, $\mathrm{Mg}^{2+}$ deficiency is well known as a potential risk factor of osteoporosis [9], as well as a cause of impaired parathyroid hormone $(\mathrm{PTH})$ secretion, which in turn dysregulates $\mathrm{Ca}^{2+}$ homeostasis [10]. Furthermore, because $\mathrm{Mg}^{2+}$ depletion has a negative effect on the synthesis of $1,25(\mathrm{OH})_{2}$ vitamin-D, bone health is negatively influenced by low $\mathrm{Mg}^{2+}$ intake [11]. In addition, in the relationship between $\mathrm{Ca}^{2+}$ and bone metabolism, PTH secretion is increased due to $\mathrm{Ca}^{2+}$ deficiency-induced hypocalcemia, and serum $\mathrm{Ca}^{2+}$ level is rapidly restored by PTH stimulating osteoclasts in the bone [12]. Therefore, fracture risk factors, such as increased bone turnover and bone loss, are influenced by excessive PTH secretion [13,14].

Meanwhile, Opuntia humifua (O. humifusa), which is a perennial plant, is a member of the Cactaceae family that grows mostly in semi-arid regions all around the world, particularly in Central and South America. In particular, O. humifusa has been cultivated in large quantities in Asan, Chungnam, Korea. The few studies that have investigated the physiological and pharmacological functions of $O$. humifusa have revealed not only its radical scavenging and anti-inflammatory effects [15] but also hypoglycemic and hypolipidemic effects [16]. On the other hand, it has been reported that Opuntia ficus-indica (O. ficus-indica), another member of the Cactaceae family, has anti-inflammatory [17], anti-cancer [18], and antioxidant effects [19], and many studies of its nutritional and pharmacological aspects have demonstrated that it contains high levels of $\mathrm{Mg}^{2+}$ and $\mathrm{Ca}^{2+}[20]$. However, although we may anticipate that $O$. humifusa also contains various minerals, few studies investigated this aspect of $O$. humifusa compared with $O$. ficus-indica. In particular, there have been no studies designed to examine the relationship between $O$. humifusa and bone metabolism.

Therefore, in this study, we investigated the effects of $O$. humifusa supplementation on bone-related hormones and bone metabolism.

\section{Results}

\subsection{Body Weight, FER and Food Intake}

As shown in Table 1, although the average body weight was the same in both groups at the beginning of the study, final body weight was slightly decreased in the EG compared with the CG after 
eight weeks of $O$. humifusa supplementation. Additionally, the FER values and food intake were not significantly different between groups.

Table 1. Changes in body weight, FER and food intake.

\begin{tabular}{ccc}
\hline & CG & EG \\
\hline Initial body weight $(\mathrm{g})$ & $235.9 \pm 3.89$ & $235.8 \pm 3.97$ \\
Final body weight $(\mathrm{g})$ & $428.2 \pm 10.86$ & $419.3 \pm 14.67$ \\
FER & $0.26 \pm 0.008$ & $0.26 \pm 0.011$ \\
Food intake (g/day) & $16.2 \pm 0.38$ & $14.9 \pm 0.16$ \\
\hline
\end{tabular}

Data were expressed as the mean $\pm \mathrm{SE}$; CG: Control diet group; EG: Experimental diet group; FER: Food efficiency ratio; ${ }^{* *} p<0.01$ compared with the CG.

\subsection{Changes in Serum Parameters}

After the eight weeks of the experiment, as shown in Table 2, there were no significant differences in the $\mathrm{Ca}, \mathrm{P}$ and ALP values between groups. However, of the hormone concentrations related to bone metabolism, the OC level was significantly higher in the EG than in the CG $(p<0.05)$, and the PTH value was significantly lower in the EG than in the CG $(p<0.05)$.

Table 2. Changes in serum parameters.

\begin{tabular}{ccc}
\hline & CG & EG \\
\hline $\mathrm{Ca}(\mathrm{mg} / \mathrm{dL})$ & $10.5 \pm 0.14$ & $10.2 \pm 0.21$ \\
$\mathrm{P}(\mathrm{mg} / \mathrm{dL})$ & $7.4 \pm 0.33$ & $7.6 \pm 0.17$ \\
$\mathrm{ALP}(\mathrm{IU} / \mathrm{L})$ & $87.0 \pm 2.55$ & $91.0 \pm 3.18$ \\
$\mathrm{OC}(\mathrm{ng} / \mathrm{mL})$ & $25.8 \pm 0.53$ & $30.4 \pm 1.41^{*}$ \\
$\mathrm{PTH}(\mathrm{pg} / \mathrm{mL})$ & $13.7 \pm 0.88$ & $10.7 \pm 0.45^{*}$ \\
\hline
\end{tabular}

Data were expressed as the mean $\pm \mathrm{SE}$; CG: Control diet group; EG: Experimental diet group; Ca: Calcium; P: Phosphorus; ALP: Alkaline phosphatase; OC: Osteocalcin; PTH: Parathyroid hormone; * $p<0.05$ compared with the CG.

\subsection{Bone Weight, BMD and BMC}

As shown in Figure 1, the femoral bone weight in the EG tended to be higher than that of the CG and also the tibial bone weight slightly higher than that of the CG, but these difference were not significant, respectively (Figure 1A,B). Additionally, the BMD of the femur and tibia of EG were significantly higher than that of the CG ( $p<0.05$; Figure 2A, $p<0.05$; Figure 2B). The tibial BMC of the EG was significantly higher than that of the CG $(p<0.01$; Figure $3 \mathrm{~B})$, and the femoral BMC of the EG tended to be higher than that of the CG (Figure 3A). 
Figure 1. The effect of $O$. humifusa supplementation on bone weight. The data were expressed as the mean \pm SE. (A) Femur, (B) Tibia. CG: Control diet group; EG: Experimental diet group.
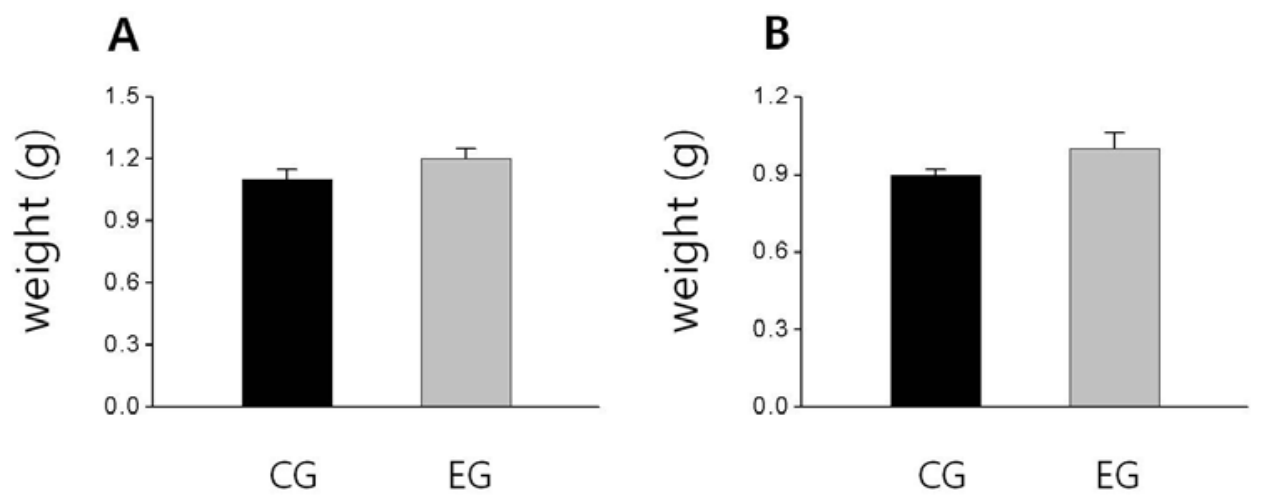

Figure 2. The effect of $O$. humifusa supplementation on bone mineral density. The data were expressed as the mean \pm SE. (A) Femur, (B) Tibia. CG: Control diet group; EG: Experimental diet group. ${ }^{*} p<0.05$ compared with the CG.
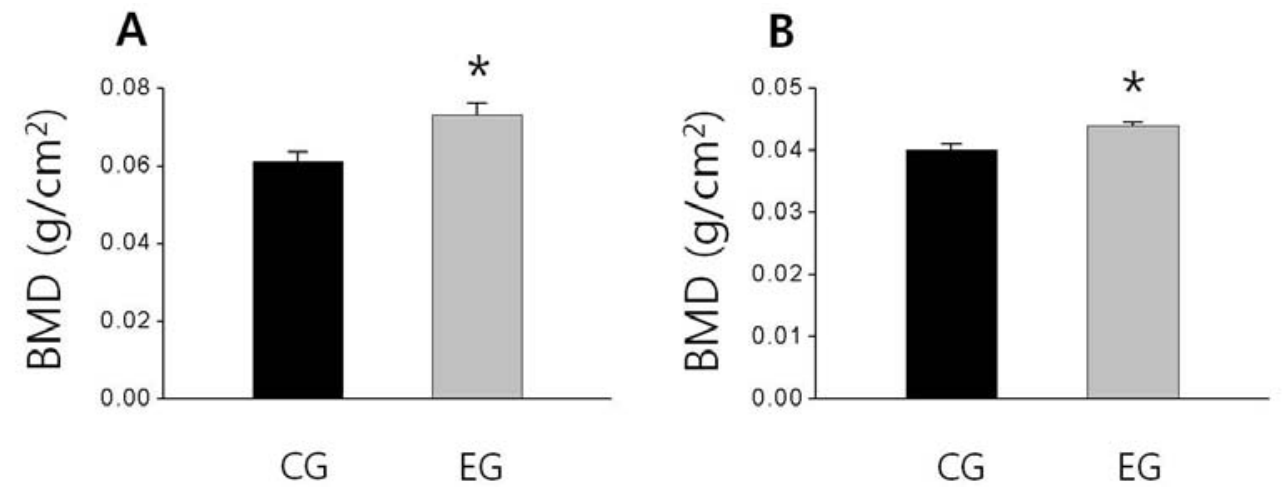

Figure 3. The effect of $O$. humifusa supplementation on bone mineral content. The data were expressed as the mean \pm SE. (A) Femur, (B) Tibia. CG: Control diet group; EG: Experimental diet group. ${ }^{* *} p<0.01$ compared with the CG.
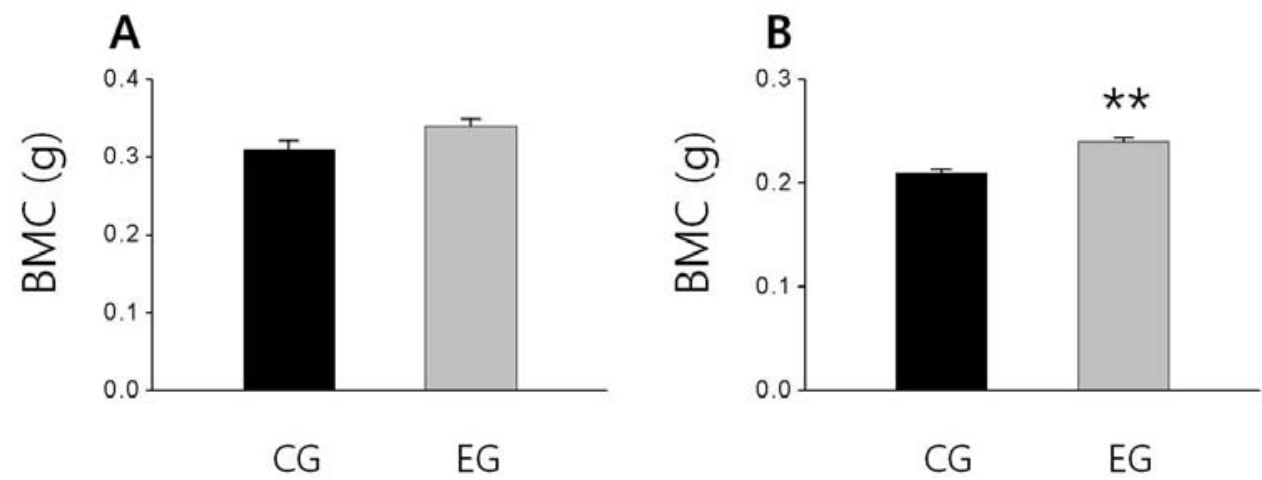

\section{Discussion}

To the best of our knowledge, this is the first study to evaluate the effects of O. humifusa supplementation on bone metabolism. Our results indicated that serum Ca, P and ALP levels were not 
significantly affected after eight weeks of treatment. However, the OC level of the EG was significantly higher than that of the OC of the CG. OC, a bone formation marker, is a major noncollagenous protein in the bone matrix that is synthesized by and released from osteoblasts [21]. Approximately $70 \%$ of the OC released from osteoblasts is combined with bone matrix and dentin cells, and the remaining $30 \%$ of the OC is secreted into the blood [22]. In a previous study, however, even though BMD was higher in rats with high OC levels [23], insufficient intake of minerals, such as $\mathrm{Mg}^{2+}$, lead to a reduction of serum OC levels [24]. Furthermore, OC is also correlated with $\mathrm{Ca}^{2+}$ levels, and approximately $99 \%$ of $\mathrm{Ca}^{2+}$ in the human body, which exists as hydroxyapatite in bones, is involved in maintaining skeletal structural strength [25]. OC has a high affinity for calcium and exhibits a compact- calcium dependent $\alpha$-helical conformation, in which the gamma-carboxylated glutamates binds and promote absorption as hydroxyapatite in the bone matrix, leading to bone mineralization [26]. Therefore, intake of sufficient minerals, including $\mathrm{Mg}^{2+}$ and $\mathrm{Ca}^{2+}$, promote an increase in OC level [27]. As a result, we might assume that supplementation with O. humifusa, which contains $\mathrm{Mg}^{2+}$ and $\mathrm{Ca}^{2+}$, would have a positive effect on bone formation and the achievement of peak bone mass in the growth period by increasing the levels of the osteogenic marker OC in the EG compared with CG.

At the same time, the PTH of the EG was significantly lower than that of the CG. Serum $\mathrm{Ca}^{2+}$ is well known to be regulated by PTH and vitamin D. When serum $\mathrm{Ca}^{2+}$ is low, increased PTH secretion stimulates calcium mobilization through bone resorption by osteoclasts [28]. Another mechanism for restoring the serum $\mathrm{Ca}^{2+}$ level to the normal range is by decreasing the excretion of $\mathrm{Ca}^{2+}$, which requires $\mathrm{Ca}^{2+}$ absorption in the intestine; this is promoted by an increased formation of $1,25(\mathrm{OH})_{2}$ vitamin-D by the activation of $25(\mathrm{OH})$ vitamin $\mathrm{D}-1 \alpha$ hydroxylase in the kidney. Therefore, because dietary calcium restrictions might cause hypocalcemia-induced osteoporosis due to increased bone resorption as well as decreased bone mass [29], repletion of calcium supplementation might have a beneficial effect on bone metabolism. In fact, Reid et al., reported that bone loss was delayed by $0.5 \sim 1 \%$ by the intake of over $800 \mathrm{mg} /$ day calcium compared with intake below $800 \mathrm{mg} /$ day for a period of 1 2 years in females with progressive bone loss [30]. In addition, a previous report has shown that $1000 \mathrm{mg} /$ day calcium and $800 \mathrm{IU} /$ day vitamin D supplementation significantly reduces PTH levels and increases BMD in the context of $\mathrm{Mg}^{2+}$ deficiency in females over the age of 65 [31]. Therefore, our data are consistent with previous findings, suggesting that $O$. humifusa provides sufficient $\mathrm{Ca}^{2+}$ and might have beneficial effects on the maintenance of the structural strength of bone, suppressing the calcium mobilization from bone by arresting PTH secretion.

Furthermore, it has been reported that $\mathrm{Mg}^{2+}$ plays a crucial role in vitamin D metabolism [32]. Serum $1,25(\mathrm{OH})_{2}$ vitamin-D concentrations are frequently low in patients with $\mathrm{Mg}^{2+}$ deficiency because $\mathrm{Mg}^{2+}$ deficiency is thought to have a negative effect on vitamin D metabolism [32]. Thus, PTH and vitamin D are essential for the physiological function of osteoblasts [33], and changes such as an increase in PTH and a reduction of $1,25(\mathrm{OH})_{2}$ vitamin-D may impair bone formation. In fact, some studies reported that diet-induced $\mathrm{Mg}^{2+}$ deficiency causes not only reduced bone mass but also skeletal fragility in a rodent model [34,35]; the observed reduction of bone mass may have been due to a reduction in the number of osteoblasts [36] by $\mathrm{Mg}^{2+}$ deficiency. However, in a previous study, $0.15 \%$ $\mathrm{Mg}^{2+}$ supplementation suppressed bone resorption due to declining PTH levels in ovariectomized rats [27]. Similarly, Stending-Lindberg et al., reported that postmenopausal women receiving two to six $125 \mathrm{mg}$ 
tablets of magnesium hydroxide daily for six months and two tablets for 18 months in a two year period exhibited increased trabecular bone density or arrested bone loss [9].

Therefore, as mentioned above, a reduction of bone formation and increase of bone resorption might be caused by the impairment of mineral intake as well as by $\mathrm{Mg}^{2+}$ and $\mathrm{Ca}^{2+}$ deficiency, and could play a negative role in bone growth. However, sufficient intake of individual nutrients such as $\mathrm{Ca}^{2+}$ and $\mathrm{Mg}^{2+}$, or functional drinks that contain replenishing minerals have a beneficial effect on BMD and BMC [37,38]. According to Kang et al., in a study of the changes of bone metabolism in growing rats caused by $\mathrm{Ca}^{2+}$ and $\mathrm{Mg}^{2+}$, long-term supplementation with deep-sea water, which is rich in $\mathrm{Mg}^{2+}$ and $\mathrm{Ca}^{2+}$, improves bone metabolism, as reflected by increased BMD, BMC and the breaking force of bones [38]. These results supported those of our present study; we calculated that the experimental diet group received approximately 2.2 times the level of $\mathrm{Mg}^{2+}$ and 1.3 times the level of $\mathrm{Ca}^{2+}$ as the control group due to the $5 \%$ O. humifusa added to the experimental diet. The mineral-rich O. humifusa supplement likely exerted positive effects on bone metabolism through the suppression of PTH secretion as well as increased intestinal $\mathrm{Ca}^{2+}$ absorption due to the activation of $1,25(\mathrm{OH})_{2}$ vitamin-D in the kidney. Additionally, further studies, such as the bone resorption markers or bone histomorphological study, are also needed to more elucidate the effect of $O$. humifusa supplementation on bone metabolism.

\section{Materials and Methods}

\subsection{Experimental Animals}

All experimental protocols were approved by the Animal Study Committee of Sunmoon University. After a one-week acclimatization period, sixteen six-week-old male Sprague-Dawley rats (Samtaco Bio Korea, Hwaseong, Korea) were randomly divided into two groups, a control diet group (CG, $n=8)$ and an experimental diet group (EG, $n=8)$ and given free access to tap water for eight weeks. Rats were housed in groups of two per cage under controlled temperature $\left(23 \pm 1{ }^{\circ} \mathrm{C}\right)$ and relative humidity $(50 \pm 5 \%)$. The light/dark cycle was automatically controlled (alternating 12-h periods) and the dark period began at 8:00 am. Food intake was measured daily and body weight was measured weekly. Food efficiency ratio (FER) was calculated as the total weight gained, divided by the total food intake for the experimental period. At the end of the experimental period, the rats were anesthetized with diethyl ether after fasting for $12 \mathrm{~h}$. Blood samples were taken from the left ventricle and serum was obtained by centrifuging the blood at $700 \times g$ for $20 \mathrm{~min}$ at $4{ }^{\circ} \mathrm{C}$. Serum samples were stored at $-70{ }^{\circ} \mathrm{C}$ until further analysis.

\subsection{Preparation of Experimental Diet}

O. humifusa was harvested in Asan, Chungnam, washed and blended using a HMF-3150S blender (Hanil Electronics, Seoul, Korea). After blending, the O. humifusa was frozen at $-70{ }^{\circ} \mathrm{C}$ and then freeze-dried (Ilshin Co., Gyeonggi, Korea). After freeze-drying, component analysis of O. humifusa was performed by Eco-Bio Korea (Gyeonggi, Korea); the results of this analysis are shown in Table 3. The composition of the control diet, which was based on AIN-76G, was $20 \%$ protein, $48 \%$ carbohydrate and $20 \%$ fat, as modified in a previous study [39]. The 5\% O. humifusa diet was made by 
substituting a portion of the carbohydrate, protein, fiber, and fat components of the control diet. During the experimental period, the diets was prepared fresh in $3 \sim 5$ day batches, and stored at $4{ }^{\circ} \mathrm{C}$ to maintain freshness.

Table 3. Components of O. humifusa.

\begin{tabular}{lc}
\hline Ingredients & Contents \\
\hline moisture $(\% \mathrm{w} / \mathrm{w})$ & 2.89 \\
ash $(\% \mathrm{w} / \mathrm{w})$ & 13.8 \\
carbohydrate $(\mathrm{g} / 100 \mathrm{~g})$ & 46.56 \\
crude protein $(\mathrm{g} / 100 \mathrm{~g})$ & 4.91 \\
crude fat $(\mathrm{g} / 100 \mathrm{~g})$ & 3.06 \\
fiber $(\mathrm{g} / 100 \mathrm{~g})$ & 28.78 \\
$\mathrm{Fe}^{2+}(\mathrm{mg} / \mathrm{g})$ & 5.76 \\
$\mathrm{Ca}^{2+}(\mathrm{mg} / 100 \mathrm{~g})$ & 2931.3 \\
$\mathrm{Mg}^{2+}(\mathrm{mg} / 100 \mathrm{~g})$ & 1227.9 \\
$\mathrm{~K}^{+}(\mathrm{mg} / 100 \mathrm{~g})$ & 2155.5 \\
$\mathrm{Na}^{+}(\mathrm{mg} / 100 \mathrm{~g})$ & 30.9 \\
$\mathrm{P}^{2+}(\mathrm{mg} / 100 \mathrm{~g})$ & 653.2 \\
\hline
\end{tabular}

\subsection{Serum Analysis}

Serum $\mathrm{Ca}, \mathrm{P}$, and alkaline phosphatase (ALP) concentrations were measured using a TBA-200FR automated analyzer (Toshiba, Tokyo, Japan), and serum osteocalcin. (OC) was analyzed by radioimmunoassay (RIA) method using the osteocalcin MYRIA (TECHNO GENETICS, Milano, Italy) assay kit. Serum concentrations of PTH were determined using the rat parathormone i-PTH ELISA kit (Wuhan EIAab Science Co., Ltd., Wuhan, China).

\subsection{Bone Weight, BMD and BMC Analysis}

Both the femur and tibia were obtained from the lower limbs, and the samples were stored in $70 \%$ ethyl alcohol until bone weight, BMD and BMC measurements were made. The bone weight was measured using an AR-2140 analytical balance (OHAUS Corporation, NJ, USA), and the BMD and $\mathrm{BMC}$ of the femur and tibia were measured with dual-energy X-ray absorptiometry (DEXA, Lunar DPXL, software version 1.0C; Madison, WI, USA).

\subsection{Statistical Analysis}

All data were analyzed using SPSS software (version 15.0 for Windows). The data are expressed as the mean $\pm \mathrm{SE}$, and values were analyzed with the independent samples $t$ test. Significance was defined as $p<0.05$. 


\section{Conclusions}

The results of the present study suggest that $O$. humifusa can be considered a functional food for the improvement of bone strength due to its ability to increase bone density via the suppression of PTH and increase of OC level.

\section{Acknowledgments}

This research was supported by Basic Science Research Program of the National Research Program through the National Research Foundation of Korea (NRF) funded by the Ministry of Education, Science and Technology (2011-0011951).

\section{References}

1. NIH Consensus development panel on osteoporosis prevention diagnosis and therapy. Osteoporosis prevention, diagnosis, and therapy. J. Am. Med. Assoc. 2001, 285, 785-795.

2. Smith, D.M.; Nance, W.E.; Kang, K.W.; Chrustian, J.C.; Johnstone, C.C. Genetic factors in determining bone mass. J. Clin. Invert. 1973, 52, 2800-2808.

3. Rana, A.R.; Michalsky, M.P.; Teich, S.; Groner, J.I.; Caniano, D.A.; Schuster, D.P. Childhood obesity: A risk factor for injuries observed at a level-1 trauma center. J. Pediatr. Surg. 2009, 44, 1601-1605.

4. Rocher, E.; Chappard, C.; Jaffre, C.; Benhamou, C.L.; Courteix, D. Bone mineral density in prepubertal obese and control children: Relation to body weight, lean mass, and fat mass. J. Bone Miner. Metab. 2008, 26, 73-78.

5. Chan, G.; Hoffman, K.; Mcmurry, M. Effects of dairy products on bone and body composition in pubertal girls. J. Pediatr. 1995, 126, 551-556.

6. Heaney, R.P. Nutritional factors in osteoporosis. Annu. Rev. Nutr. 1993, 13, 287-316.

7. Fassler, A.L.C.; Bonjour, J.P. Osteoporosis as a pediatric problem. Pediatr. Clin. North Am. 1995, 42, 811-824.

8. Rude, R.K.; Oldham, S.H. Disorders of Magnesium Metabolism. In The metabolic and molecular Basis of Acquired Disease; Cohen, R.D., Lewis, B., Alberti, K.G.M.M., Denmon, A.M., Eds.; Balliere Tindall: London, UK, 1990; pp. 1124-1148.

9. Stending-Lindberg, G.; Tepper, R.; Leichter, I. Trabecular bone density in a two-year controlled trial of peroral magnesium in osteoporosis. Magnesium Res. 1993, 6, 155-163.

10. Rude, R.K.; Oldham, S.B.; Sharp, C.F., Jr.; Singer, F.R. Parathyroid hormone secretion in magnesium deficiency. J. Clin. Endocrinol. Metab. 1978, 47, 800-806.

11. Reginster, J.Y.; Strause, L.; Deroisy, R.; Lecart, M.P.; Saltman, P.; Franchimont, P. Preliminary report of decreased serum magnesium in postmenopausal osteoporosis. Magnesium 1989, 8, 106-109.

12. Campbell, L. Thyroid and parathyroid hormones and calcium homeostasis. Anaesth. Intens. Care Med. 2011, 12, 465-468.

13. Sahota, O.; Masud, T.; San, P.; Hosking, D.J. Vitamin D insufficiency increases bone turnover markers and enhances bone loss at the hips in patients with established osteoporosis. Clin. Endocrinol. 1999, 51, 217-221. 
14. LeBoff, M.S.; Kohlmeier, L.; Hurwitz, S.; Franklin, J.; Wright, J.; Glowacki, J. Occult vitamin D deficiency in post menopausal US women with acute hip fracture. J. Am. Med. Assoc. 1999, 281, 1505-1511.

15. Cho, J.Y.; Park, S.C.; Kim, T.W.; Kim, K.S.; Song, J.C.; Kim, S.K.; Lee, H.M.; Sung, H.J.; Park, H.J.; Song, Y.B.; et al. Radical scavenging and anti-inflammatory activity of extracts from Opuntia humifusa Raf. J. Pharm. Pharmacol. 2006, 58, 113-119.

16. Hahm, S.W.; Park, J.; Son, Y.S. Opuntia humifusa stems lower blood glucose and cholesterol levels in streptozotocin-induced diabetic rats. Nutr. Res. 2011, 31, 479-487.

17. Park, E.H.; Kahng, J.H.; Paek, E.A. Studies on the pharmacological action of cactus: Identification of its anti-inflammatory effect. Arch. Pharm. Res. 1998, 21, 20-34.

18. Chavez-Santoscoy, R.A.; Gutierrez-Uribe, J.A.; Serna-Saldivar, S.O. Phenolic composition, antioxidant capacity and in vitro cancer cell cytotoxicity of nine prickly pear (Opuntia spp.) juices. Plant Foods Hum. Nutr. 2009, 64, 146-152.

19. Lee, J.C.; Kim, H.R.; Kim, J.; Jang, Y.S. Antioxidant property of an ethanol extract of the stem of Opuntia ficus-indica var. Saboten. J. Agric. Food Chem. 2002, 50, 6490-6496.

20. Hernández-Urbiola, M.I.; Pérez-Torrero, E.; Rodríguez-García, M.E. Chemical analysis of nutritional content of prickly pads (Opuntia ficus indica) at varied ages in an organic harvest. Int. J. Environ. Res. Public Health 2011, 8, 1287-1295.

21. Brown, J.P.; Delmas, P.D.; Malaval, L.; Chapuy, M.C.; Delmas, P.D.; Edouard, C.; Meunier, P.J. Serum bone Gla protein: A specific marker for bone formation in post-menopausal osteoporosis. Lancet 1984, 1, 1091-1093.

22. Power, M.J.; Fottrell, P.F. Osteocalcin: Diagnostic methods and clinical applications. Crit. Rev. Clin. Lab. Sci. 1991, 28, 287-335.

23. Godfrey, J.K.; Kayser, B.D.; Gomez, G.V.; Bennett, J.; Jaque, S.V.; Sumida, K.D. Interrupted resistance training and BMD in growing rats. Int. J. Sports Med. 2009, 30, 579-584.

24. Carpenter, T.O.; Mackowiak, S.J.; Troiano, N.; Gundberg, C.M. Osteocalcin and its message: Relationship to bone histology in magnesium-deprived rats. Am. J. Physiol. 1992, 263, 107-114.

25. Broadus, A.E. Physiological Functions of Calcium, Magnesium, and Phosphorus and Mineral ion Balance. In Primer on the Metabolic Bone Diseases and Disorders of Mineral Metabolism; Favus, M.J., Ed.; Raven Press: New York, NY, USA, 1993, pp. 41-46.

26. Jagtap, V.R.; Ganu, J.V.; Nagane, N.S. BMD and serum intact osteocalcin in postmenopausal osteoporosis women. Indian J. Clin. Biochem. 2011, 26, 70-73.

27. Toba, Y.; Kajita, Y.; Masuyama, R.; Takada, Y.; Suzuki, K.; Aoe, S. Dietary magnesium supplementation affects bone metabolism and dynamic strength of bone in ovariectomized rats. J. Nutr. 2000, 130, 216-220.

28. Kumar, R.; Thompson, J.R. The regulation of parathyroid hormone secretion and synthesis. J. Am. Soc. Nephrol. 2011, 22, 216-224.

29. Creedon, A.; Cashman, K.D. The effect of calcium intake on bone composition and bone resorption in the young growing rat. Br. J. Nutr. 2001, 86, 453-459.

30. Reid, I.R.; Ames, R.W.; Evans, M.C.; Gamble, G.D.; Sharpe, S.J. Effect of calcium supplementation on bone loss in postmenopausal women. N. Engl. J. Med. 1993, 328, 460-464. 
31. Grados, F.; Brazier, M.; Kamel, S.; Duver, S.; Heurtebize, N.; Maamer, M.; Mathieu, M.; Garabédian, M.; Sebert, J.L.; Fardellone, P. Effects on bone mineral density of calcium and vitamin D supplementation in elderly women with vitamin D deficiency. Joint Bone Spine 2003, 70, 203-208.

32. Rude, R.K.; Adams, J.S.; Ryzen, E.; Endres, D.B.; Niimi, H.; Horst, R.L.; Haddad, J.G., Jr.; Singer, F.R. Low serum concentrations of 1,25-dihydroxyvitamin and in human magnesium deficiency. J. Clin. Endocrinol. Metab. 1985, 61, 933-940.

33. Rude, R.K.; Gruber, H.E.; Norton, H.J.; Wei, L.Y.; Frausto, A.; Mills, B.G. Bone loss induced by dietary magnesium reduction to $10 \%$ of the nutrient requirement in rats is associated with increased release of substance $\mathrm{P}$ and tumor necrosis factor- $\alpha$. J. Nutr. 2004, 134, 79-85.

34. Kenney, M.A.; McCoy, H.; Williams, L. Effects of magnesium deficiency on strength, mass and composition of rat femur. Calcif. Tissue Int. 1994, 54, 44-49.

35. Boskey, A.L.; Rimnac, C.M.; Bansal, M.; Federman, M.; Lian, J.; Boyan, B.D. Effect of short-term hypomagnesemia on the chemical and mechanical properties of rat bone. J. Orthop. Res. 1992, 10, 774-783.

36. Rude, R.K.; Kirchen, M.E.; Gruber, H.E.; Meyer, M.H.; Luck, J.S.; Crawford, D.L. Magnesium deficiency-induced osteoporosis in the rat: Uncoupling of bone formation and bone resorption. Magnes. Res. 1999, 12, 257-267.

37. Kang, J.; Kwon, D.; Park, J.; Shin, Y.O.; Lee, J.B.; Igawa, S.; Song, Y. Deep-sea water supplementation and swimming exercise improves bone metabolism in growing rats fed a high-fat diet. Food Sci. Biotechnol. 2011, 20, 665-670.

38. Bogden, J.D.; Kemp, F.W.; Huang, A.E.; Shapses, S.A.; Ambia-Sobhan, H.; Jagpal, S.; Brown, I.L.; Birkett, A.M. Bone mineral density and content during weight cycling in female rats: Effects of dietary amylase-resistant starch. Nutr. Metab. 2008, 26, 5-34.

39. Kim, Y.J.; Park, T.S. Genes are differentially expressed in the epididymal fat of rats rendered obese by a high-fat diet. Nutr. Res. 2008, 28, 414-422.

(C) 2012 by the authors; licensee MDPI, Basel, Switzerland. This article is an open access article distributed under the terms and conditions of the Creative Commons Attribution license (http://creativecommons.org/licenses/by/3.0/). 